\title{
CMP Honors Byron J. Good in 2018
}

\author{
Atwood D. Gaines ${ }^{1}$
}

Published online: 24 February 2018

(C) Springer Science+Business Media, LLC, part of Springer Nature 2018

In this volume year, volume 42 for 2018, Culture, Medicine and Psychiatry is pleased to honor the work of Professor Byron J. Good and in so doing continue an earlier practice of honoring still-active notables (e.g., Arthur Kleinman in 2016). Professor Good received the Lifetime Achievement Award from the Society for Psychological Anthropology presented in New Orleans in 2017. He is currently Professor in the Department of Global Health and Social Medicine at Harvard Medical School and Professor of Anthropology at Harvard University. Dr. Good is also a former editor of this Journal (1986-2004).

As per usual with our honorees, Dr Good's work and career will be honored with a running line in each issue of CMP this year and, at year's end, we will provide an overview of his illustrious career and a full bibliography of his published works. These include indispensable co-edited works with Arthur Kleinman, Depression and Culture, and with Mary-Jo DelVecchio Good, Paul Brodwin and Kleinman, Pain as Human Experience, as well as his Lewis Henry Morgan Lecture, Medicine, Rationality and Experience. We are pleased to honor this path-breaking figure in medical social science in general, and medical anthropology in particular.

Atwood D. Gaines

atwood.gaines@case.edu

1 Case Western Reserve University, Cleveland, OH, USA 